\title{
Real Time Observation of the Formation of Hollow Nanostructures through Solid State Reactions
}

Huang-Yen Lai, ${ }^{\S, \dagger}$ Chun-Wei Huang, ${ }^{\S} \dagger$ Chung-Hua Chiu, ${ }^{\S}, \dagger$ Chun-Wen Wang, ${ }^{\S}$ Jui-Yuan Chen, ${ }^{\S}$ Yu-Ting Huang, ${ }^{\S}$ Kuo-Chang $\mathrm{Lu}^{\dagger}{ }^{\dagger}$ and Wen-Wei $\mathrm{Wu}^{*}, \S$

${ }^{\S}$ Department of Materials Science and Engineering, National Chiao Tung University, No. 1001, University Rd, East Dist., Hsinchu City, 300, Taiwan

${ }^{\ddagger}$ Department of Materials Science and Engineering, National Cheng Kung University, Tainan, 701, Taiwan

\section{Supporting Information}

ABSTRACT: We demonstrate the formation of hollow nickel germanide nanostructures of $\mathrm{Ni}-\mathrm{Ge}$ core-shell nanoparticles by solid state reactions. The structural evolutions of nickel germanide hollow nanostructures have been investigated in real-time ultrahigh vacuum transmission electron microscopy (UHV-TEM). Annealed above $450{ }^{\circ} \mathrm{C}$, the nonequilibrium interdiffusion of core and shell species occurred at the interface; thus, $\mathrm{Ni}$ germanide hollow nanostructures were formed by solid state reactions involving the Kirkendall effect. In addition, the different hollow nanostructures formed from different core diameters of $\mathrm{Ni}-\mathrm{Ge}$ core-shell nanoparticles have been studied. Also, we propose the mechanism with effects of the size and annealing duration on the solid state

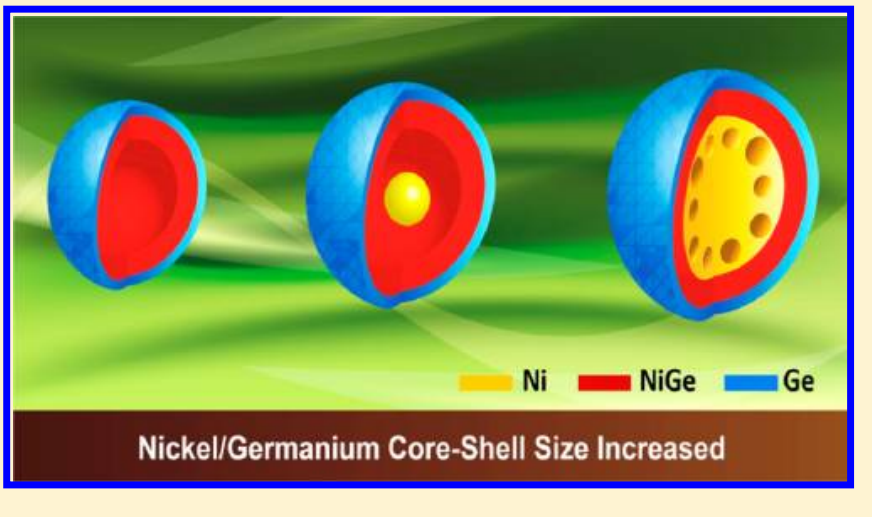
reactions based on the Kirkendall effect.

$\mathrm{O}$ ver the past decade, hollow nanostructures have emerged as new functional materials and have attracted applications in high efficiency catalysis, ${ }^{1-3}$ sensing, ${ }^{4-6}$ lithiumion batteries, ${ }^{7-11}$ and biomedical science and engineering ${ }^{12-16}$ due to their unique and novel structures, such as high surfaceto-volume ratio and a large pore volume. There are many approaches commonly used to synthesize the hollow nanostructures, including template-mediated methods, ${ }^{17-20}$ chemical etching, ${ }^{21,22}$ and recently, galvanic replacement ${ }^{23,24}$ and the nanoscale Kirkendall effect. ${ }^{25-27}$ Among them, the nanoscale Kirkendall effect is almost through the solid-gas state system $^{25,28}$ and solid-liquid state system, ${ }^{26,27}$ providing a novel and effective method to fabricate hollow nanostructures. In contrast, fabricating hollow nanostructures through solidsolid state reactions ${ }^{29}$ is rare in related studies, which is attributed to the difficult preparation of the solid-solid state core-shell system with appropriate coating properties. Although transition metal-group IV compounds formation has been reported through the Kirkendall effect, ${ }^{30}$ the reaction process of solid state reactions to form hollow nanostructures via the Kirkendall effect mechanism has never been observed directly, even including various assumptions during the actual reaction process. Therefore, the $\mathrm{Ni}-\mathrm{Ge}$ system was used as the model system of extremely different interdiffusion rates between $\mathrm{Ni}$ and $\mathrm{Ge}$, which is helpful for observing diffusion behaviors at the interface via the Kirkendall effect. Furthermore, the nickel germanide, the product of this system, exhibits many excellent properties, such as wide temperature stability, facile chemical processing, and low resistivity, having been demonstrated to be a promising Schottky barrier source/drain material in Ge-based p-channel metal oxide semiconductor field effect transistors (MOSFETs). ${ }^{31-35}$ However, hollow nanostructures of nickel germanides have never been synthesized. In this work, the formation of hollow nickel germanide nanostructures by solid state reactions of $\mathrm{Ni}-\mathrm{Ge}$ core-shell nanoparticles has been investigated. The different hollow nanostructures formed from different core diameters of $\mathrm{Ni}-\mathrm{Ge}$ core-shell nanoparticles are discussed. Additionally, in situ transmission electron microscopy (TEM) is a powerful tool for atomiclevel observation, including phase/shape transformations, ${ }^{36-38}$ electron transport behaviors, ${ }^{39-42}$ and solid-liquid interactions in wet cells. ${ }^{43}$ Also, utilizing the in situ observation, the formation mechanism of hollow nanostructures has been demonstrated. Although the formation behavior can be driven by electron beam irradiation, it can be neglected in our case because we found that some core-shell structures successfully reacted to be yolk-shell structures without electron beam irradiation. This may enhance the applications in the fabrication of other nanosystems with different hollow morphologies based on the mechanism proposed in this study.

Received: January 12, 2014

Accepted: March 26, 2014

Published: March 26, 2014 


\section{EXPERIMENTAL SECTION}

$\mathrm{Ni}-\mathrm{Ge}$ core-shell nanoparticle arrays with various diameters and intervals were fabricated by utilizing an e-beam lithography (EBL) system and designed pattern on a $\mathrm{Si}_{3} \mathrm{~N}_{4}$ membrane window grid. The process is shown in Figure S-1, Supporting Information. PMMA was coated on the $\mathrm{Si}_{3} \mathrm{~N}_{4}$ membrane, and then, nanoparticle arrays were defined by e-beam lithography. After the development process, $\mathrm{Ni}$ film was deposited on the substrate by e-beam evaporator (EBE). Following the lift-off process in the acetone, the $\mathrm{Ni}$ nanoparticle arrays were prepared. Then, Ge film was deposited to cover the $\mathrm{Ni}$ nanoparticle arrays by EBE. A field emission scanning electron microscope (FESEM, JEOL JSM-6500F) was used to examine the morphology of core-shell nanoparticle arrays. Highresolution lattice imaging and line scan were performed by a high resolution transmission electron microscope (HRTEM, JEOL 2100F) equipped with an energy dispersive spectrometer (EDS). To observe diffusion behaviors at the interface between the core and shell, the cross-sectional sample of Ni-Ge coreshell nanoparticle was prepared with focused ion beam (FIB). The Ni-Ge core-shell nanoparticle capped with $100 \mathrm{~nm}$-thick $\mathrm{SiO}_{2}$ was fabricated on a $\mathrm{Si}_{3} \mathrm{~N}_{4}$ membrane. The $\mathrm{Pt}$ and $\mathrm{SiO}_{2}$ film typically deposited on the $\mathrm{Ni}-\mathrm{Ge}$ core-shell nanoparticle was utilized to prevent the sample from ion beam sputtering damage and $\mathrm{Pt}$ diffusion during annealing, respectively. After that, the cross-sectional sample was then annealed and observed by in situ TEM. During the reaction, the temperature was raised to $450{ }^{\circ} \mathrm{C}$ to investigate the morphological and structural change of the $\mathrm{Ni}-\mathrm{Ge}$ core-shell nanoparticle by solid state reactions via the Kirkendall effect.

\section{RESULTS AND DISCUSSION}

Figure 1a,b shows SEM images of Ni-Ge core-shell nanoparticle arrays fabricated by utilizing the e-beam lithography system and designed pattern. It can be clearly seen that the outer shell was coated over the inner core completely. Figure 1c presents a typical TEM image of a NiGe core-shell nanoparticle; the strong contrast between the dark core and the relatively bright edge is evidenced by their compact contact. Notably, the diameter of the inner $\mathrm{Ni}$ nanoparticle is about $83 \mathrm{~nm}$, and the thickness of the outer $\mathrm{Ge}$ shell is about $80 \mathrm{~nm}$. Furthermore, the amorphous structure of the outer Ge shell results in their ambiguous contour indicated by dashed lines, while the inner $\mathrm{Ni}$ core has a polycrystalline structure. Figure $2 \mathrm{~b}$ shows the TEM image of a Ni-NiGe yolk-shell nanostructure obtained during annealing at $450{ }^{\circ} \mathrm{C}$ for $30 \mathrm{~min}$ through the Kirkendall effect. As shown in Figure $1 \mathrm{~d}$, the inner $\mathrm{Ni}$ atoms diffused mostly into the outer Ge shell. The interior of the Ni-Ge core-shell generated a void of about $100 \mathrm{~nm}$ in diameter. It shows that around $50 \mathrm{~nm}$ of the inner $\mathrm{Ni}$ nanoparticle remained unreacted. The hollow sphere was found uniform, and the formed $\mathrm{NiGe}$ shell thickness was about 20-30 nm. Figure 1e,f shows HRTEM images of the Ni-NiGe yolk-shell nanostructure marked in Figure 1d, respectively. The lattice spacings of the shell are 0.249 and $0.191 \mathrm{~nm}$, which correspond to (111) and (211) planes of the orthorhombic $\mathrm{NiGe}$ phase, and the angle between the planes is $84.96^{\circ}$. On the other hand, the lattice spacings of the yolk are 0.2046 and $0.2063 \mathrm{~nm}$, corresponding to $(1 \overline{1} 1)$ and $(11 \overline{1})$ planes of the cubic $\mathrm{Ni}$ phase, and the angle between the planes is $70.53^{\circ}$. In addition, NiGe phase can be formed through solid state reactions of $\mathrm{Ge}$ and $\mathrm{Ni}$, which is highly attractive due to its low

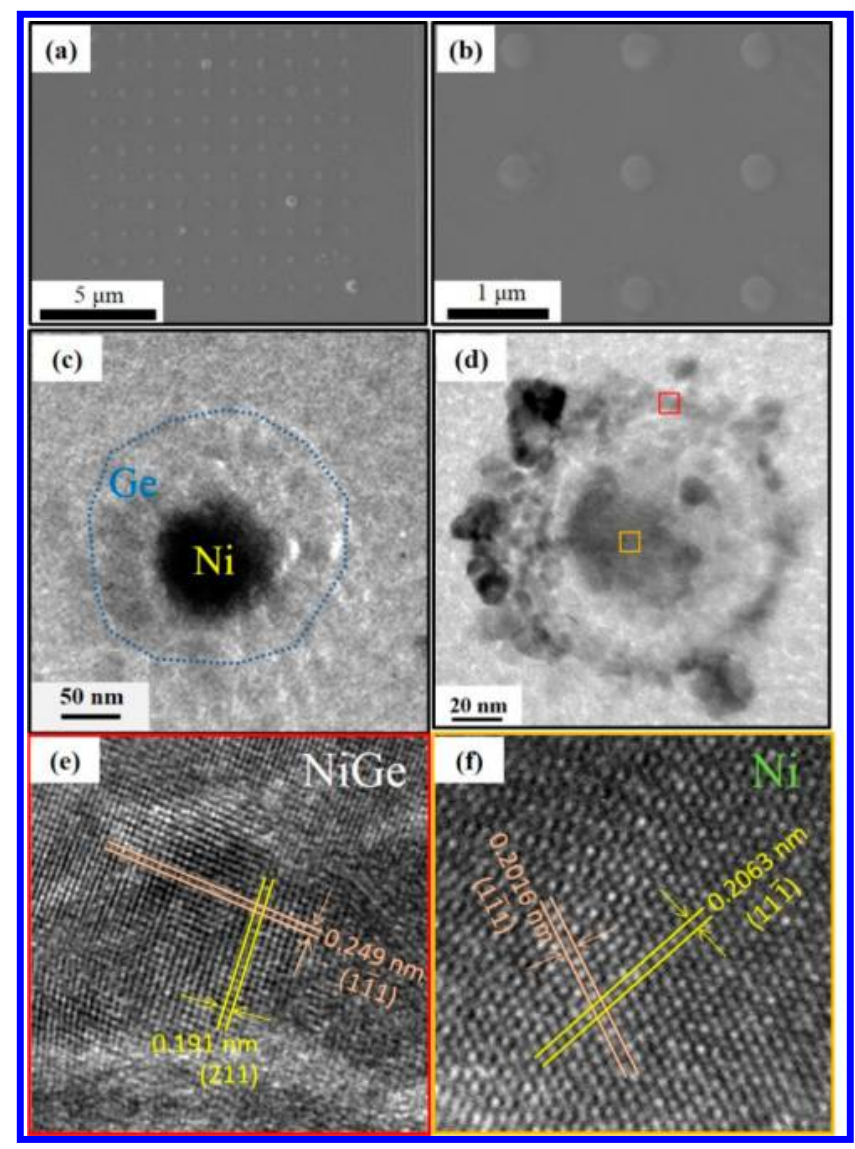

Figure 1. (a) and (b) Ni-Ge core-shell nanoparticles of different sizes fabricated on a $\mathrm{Si}_{3} \mathrm{~N}_{4}$ membrane substrate. (c) TEM image of a $\mathrm{Ni}$ core covered by a Ge shell. (d) TEM image of a Ni-NiGe yolkshell nanoparticle formed during annealing at $450{ }^{\circ} \mathrm{C}$. (e) The HRTEM image of the NiGe shell. (f) The HRTEM image of the Ni core.

processing temperature of about $250{ }^{\circ} \mathrm{C}$. In this study, the demand for the purpose of imaging the real time reaction process stimulated us to raise the reaction temperature up to $450{ }^{\circ} \mathrm{C}$ to decrease the reaction time although the $\mathrm{NiGe}$ can indeed react at low processing temperature of about $250{ }^{\circ} \mathrm{C}$. Figure S-2a,c, Supporting Information, shows the TEM images and the related EDS spectra revealing the composition and structure of the Ni-NiGe yolk-shell nanostructure. The EDS line scan in Figure S-2b,d, Supporting Information, explicitly shows the compositional profile after the reaction. The intensity profile demonstrates the $\mathrm{Ni}-\mathrm{NiGe}$ yolk-shell nanostructures and confirms the outward diffusion of $\mathrm{Ni}$ while Ge mostly remains, indicating that the partially hollow interior has been formed via the Kirkendall effect. In addition, EDS mapping of Ni-NiGe yolk-shell nanoparticle has further confirmed this viewpoint in Figure S-2e, Supporting Information. Figure $2 \mathrm{a}-\mathrm{c}$ shows the TEM images of $\mathrm{Ni}-\mathrm{Ge}$ core-shell nanoparticles during the same reaction condition, annealing at $450{ }^{\circ} \mathrm{C}$ for $30 \mathrm{~min}$ via the Kirkendall effect, with core diameters of 50, 80, and $200 \mathrm{~nm}$.

Comparing Figure $2 a-c$ reveals that increasing the core diameter leads to a significant change in the morphologies of fully hollow structures, yolk-shell structures, and porous structures, respectively. Supporting video-1, ac500134u_si_002.avi, Supporting Information, shows the formation process of a $\mathrm{Ni}-\mathrm{NiGe}$ yolk-shell nanostructure during 


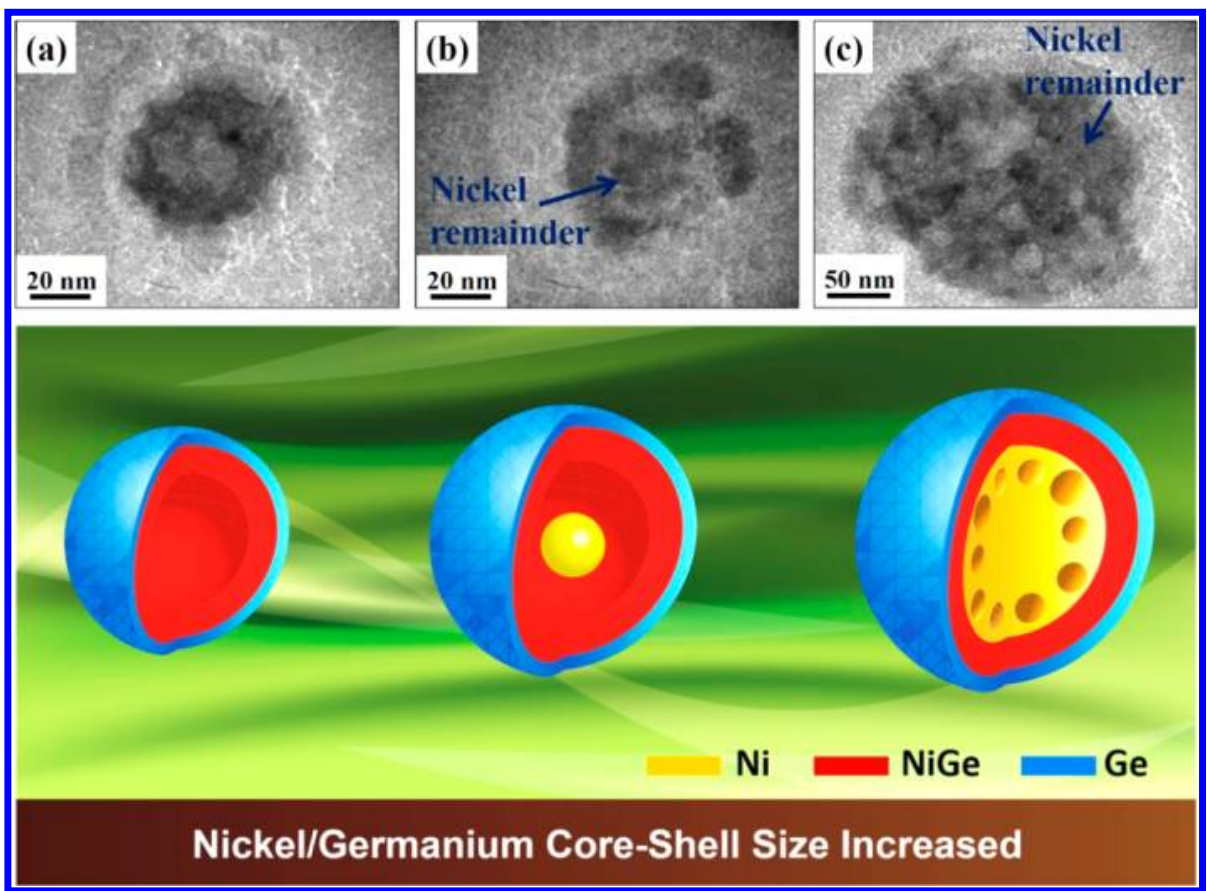

Figure 2. Different morphologies and structures of hollow nickel germanide nanoparticles with different core diameters; (a) fully formed hollow structure, (b) yolk-shell structure, and (c) porous structure.
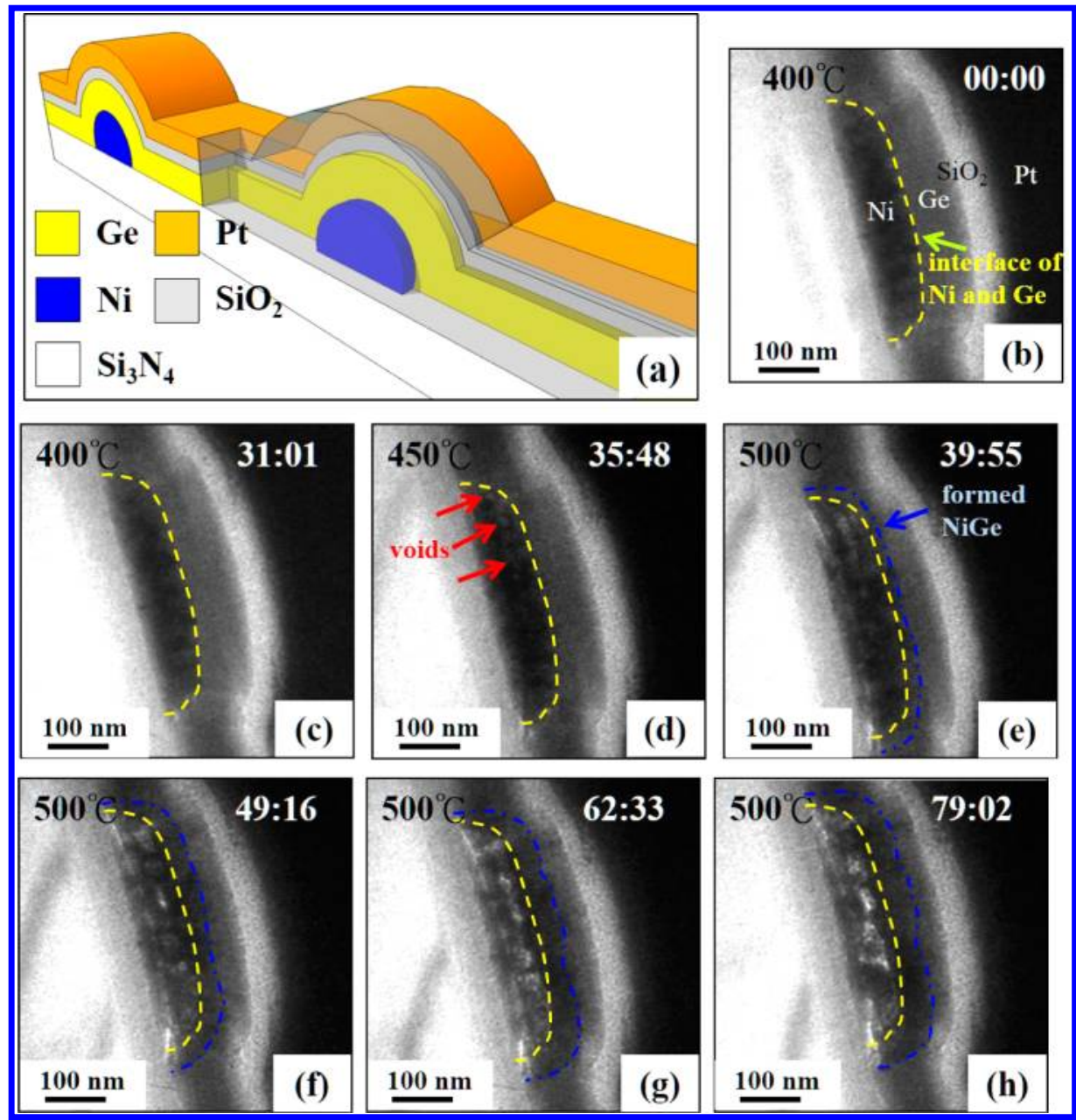

Figure 3. (a) Schematic illustration of a Ni-Ge core-shell cross-sectional FIB sample. (b)-(h) A time-resolved series of TEM images captured from an in situ TEM video, showing the void formation process of a $\mathrm{Ni}-\mathrm{Ge}$ core-shell nanoparticle during annealing above $400{ }^{\circ} \mathrm{C}$. 


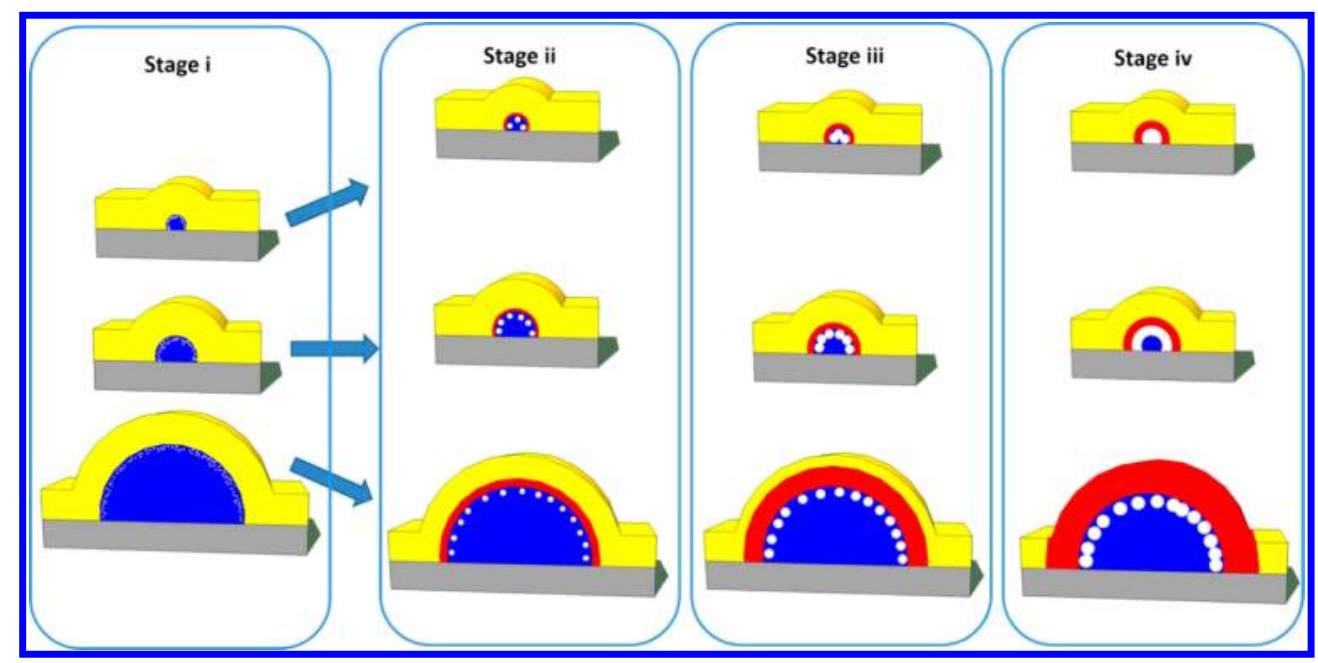

Figure 4. Schematic illustration of the hollow structures formed via the Kirkendall effect. Stage (i) Vacancies are formed through the nonequilibrium interdiffusion of core and shell species via the Kirkendall effect at specific temperatures. Stage (ii) Saturated vacancies agglomerate to form numerous voids by thermal vibration at specific temperatures, and the reactant is formed between the core and shell. Stage (iii) Voids grow gradually with agglomeration of adjacent small voids, which is influenced by the size of the core. Stage (iv) With the size effect, different nanostructures are formed.

annealing at $450{ }^{\circ} \mathrm{C}$. A similar behavior about covered shells of different core diameters to form hollow nanostructures of different morphologies was discussed from the oxidation of $\mathrm{Ni}$ nanoparticles. ${ }^{44}$ During the treatment at $500{ }^{\circ} \mathrm{C}$ for $2 \mathrm{~h}$, the $\mathrm{Ni}$ nanoparticles with $96 \mathrm{~nm}$ diameter were formed to be $\mathrm{Ni}-\mathrm{NiO}$ porous nanostructures rather than a large void within hollow nanostructures of Ni nanoparticles with diameters below $26 \mathrm{~nm}$ heated at $300{ }^{\circ} \mathrm{C}$ for $2 \mathrm{~h}$.

Furthermore, in order to directly observe the atomic interdiffusion behavior at the interface between the core, shell, and the formed reactant movement profile via the Kirkendall effect, the cross-sectional sample of Ni-Ge coreshell nanoparticle was prepared with FIB as illustrated in Figure 3. The schematic illustration of the cross-sectional FIB sample is shown in Figure 3a, and each component is labeled accordingly. Figure $3 b-h$ is captured from an in situ TEM video, revealing the Kirkendall voids and yolk-shell Ni-NiGe nanostructure. Figure $3 \mathrm{~b}$ shows the cross-sectional TEM image of the $\mathrm{Ni}-\mathrm{Ge}$ core-shell nanoparticle before annealing. The yellow dash line denotes the interface between $\mathrm{Ni}$ and $\mathrm{Ge}$. Figure $3 \mathrm{c}$ shows the cross-sectional TEM image during annealing at $400{ }^{\circ} \mathrm{C}$ for about $30 \mathrm{~min}$ as the voids and reactant were not found. This may be attributed to the slow interdiffusion rates of $\mathrm{Ni}$ and $\mathrm{Ge}$ at $400{ }^{\circ} \mathrm{C}$. When the temperature ramped to $450{ }^{\circ} \mathrm{C}$, several small voids of about 6$7 \mathrm{~nm}$ in dimension clearly appeared in Figure 3d, formed within the $\mathrm{Ni}$ near the original interface during annealing for less than $5 \mathrm{~min}$. The result indicates that $\mathrm{Ni}$ has a faster diffusion rate than Ge. However, neither the contrast of the reactant nor the interface movement between $\mathrm{Ni}$ and the reactant can be clearly observed. Figure $3 \mathrm{e}$ shows the cross-sectional TEM image of the sample as ramped to $500{ }^{\circ} \mathrm{C}$ for about $4 \mathrm{~min}$ with the faster diffusion of $\mathrm{Ni}$ outward; some voids begin to grow gradually with consumption of adjacent smaller voids. We propose that the thermodynamic driving force of the phenomenon is to reduce the surface energy through agglomeration of adjacent small voids. In addition, the contrast of the reactant appeared between the original interface and outer Ge. Figure 3f shows the cross-sectional TEM image of the sample annealed at 500 ${ }^{\circ} \mathrm{C}$ for over $10 \mathrm{~min}$. We can see that these large voids of about $15 \mathrm{~nm}$ in dimension grew continuously within the Ni near the original interface, and the thickness of the formed $\mathrm{NiGe}$ shell was about $40 \mathrm{~nm}$. When the sample was annealed at $500{ }^{\circ} \mathrm{C}$ for $25 \mathrm{~min}$, these large voids grew until they connected with each other as shown in Figure 3g. During the diffusion process, inner nickel atoms diffused outward into the outer germanium shell only through a small number of connected regions. Figure $3 \mathrm{~h}$ shows the cross-sectional TEM image of the sample annealed at $500{ }^{\circ} \mathrm{C}$ for $40 \mathrm{~min}$. Notably, the thickness of the formed NiGe shell was about $45 \mathrm{~nm}$ and hardly thickened, resulting from the fact that excess nickel atoms were almost isolated by these voids near the original interface; thus, they were unable to diffuse outward. This was probably the reason why the yolk-shell nanostructure formed during the reaction. Additionally, this initial interface marked by yellow dash contour is likely to be pinned at the original location in our model system, probably resulting from the effect that, while $\mathrm{Ni}$ atoms diffuse outward to the outer germanium shell, the accompanied voids would tend to agglomerate adjacent small voids into a larger one with low mobility. Though this behavior is attributed to reducing the surface energy, the voids agglomeration has particular saturation that prevents them from opposite diffusion to the initial interface, indicative of the negligible movement of the mark interface, as displayed in Figure 3. Additionally, we noted that the solid state reaction between $\mathrm{Ni}-\mathrm{Ge}$ core-shell systems may occur uniformly around the $\mathrm{Ni}-\mathrm{a}-\mathrm{Ge}$ interface instead of the heterogeneous boundary among $\mathrm{Ni}$ core, $\mathrm{Ge}$ shell, and nitride membrane with relatively high energy in our case. On the other hand, there were many vacancies inside a-Ge layer with much larger surface energy than that of the heterogeneous boundary at the reaction temperature. As a result, we propose that the main driving force of the outward diffusion of $\mathrm{Ni}$ atoms to Ge shell is likely the reduction in energy by mixing the two atoms into chemical compound, which is associated with the increase in the entropy of the $\mathrm{Ni}-\mathrm{Ge}$ core-shell nanostructure as the Kirkendall effect.

A schematic illustration depicting the solid state reaction process of $\mathrm{Ni}-\mathrm{Ge}$ core-shell with different sizes via the Kirkendall effect is presented in Figure 4. The mechanism is mainly divided into four stages: (i) Vacancies are formed through the nonequilibrium interdiffusion of core and shell species via the Kirkendall effect at specific temperatures. (ii) 
Saturated vacancies agglomerate to form numerous voids by thermal vibration at specific temperatures, and the reactant is formed between the core and shell. (iii) Voids grow gradually with agglomeration of adjacent small voids, which is influenced by the size of the core. (iv) With the size effect, different nanostructures are formed.

In stage (i) and stage (ii), core-shell nanoparticles with small, medium, and large core sizes undergo the same reaction where small voids are formed at the interface between the core and shell by saturated vacancies via the Kirkendall effect. In stage (iii) and stage (iv), for core-shell nanoparticles with a small core size, the small voids grow into a larger void. Eventually, the hollow nanostructure is formed. For core-shell nanoparticles with a medium core size, the voids grow but the core atoms cannot diffuse outward since the core is separated by the voids near the interface so that the yolk-shell nanostructure is formed. On the other hand, for core-shell nanoparticles with a large core size, the voids grow and there are sufficient core atoms diffusing outward; however, the original shell has formed to be the reactant entirely so that the diffusion behavior is interrupted and porous nanostructures appear.

\section{CONCLUSIONS}

In summary, the $\mathrm{Ni}-\mathrm{NiGe}$ yolk-shell nanostructure has been formed from as-fabricated controllable $\mathrm{Ni}-\mathrm{Ge}$ core-shell nanoparticles during annealing at $450{ }^{\circ} \mathrm{C}$ via the Kirkendall effect. With in situ TEM, the formation of Ni-NiGe yolk-shell nanostructures by solid state reactions has been observed directly. During the reactions, voids were formed within the $\mathrm{Ni}$ near the interface, and the remaining inner nickel was almost isolated to be a Ni-NiGe yolk-shell nanostructure. Moreover, nanostructures of different morphologies were formed, including fully hollow, yolk-shell, and porous nanostructures from $\mathrm{Ni}-\mathrm{Ge}$ core-shell nanoparticles of different core sizes. Also, we have proposed the mechanisms of the solid state reaction process for the $\mathrm{Ni}-\mathrm{Ge}$ core-shell nanostructures of different dimensions. The unique hollow nanostructures may be applied as new functional materials in high efficiency catalysis, sensing, and drug delivery.

\section{ASSOCIATED CONTENT}

\section{S Supporting Information}

Schematic illustration of the fabrication process of $\mathrm{Ni}-\mathrm{Ge}$ core-shell nanoparticles, EDS line scan of the Ni-NiGe yolkshell nanostructure, and two in situ TEM videos. This material is available free of charge via the Internet at http://pubs.acs.org.

\section{AUTHOR INFORMATION}

\section{Corresponding Author}

*E-mail: wwwu@mail.nctu.edu.tw.

\section{Author Contributions}

${ }^{\dagger}$ H.-Y.L., C.-W.H., and C.-H.C. contributed equally

\section{Notes}

The authors declare no competing financial interest.

\section{ACKNOWLEDGMENTS}

W.-W.W. and K.-C.L. acknowledge the support by National Science Council through Grants NSC 102-2221-E-009-039, NSC 100-2628-E-009-023-MY3, and NSC 102-2221-E-006077-MY3.

\section{REFERENCES}

(1) Li, H.; Bian, Z.; Zhu, J.; Zhang, D.; Li, G.; Huo, Y.; Li, H.; Lu, Y. I. Am. Chem. Soc. 2007, 129 (27), 8406-8407.

(2) Zeng, Y.; Wang, X.; Wang, H.; Dong, Y.; Ma, Y.; Yao, J. Chem. Commun. 2010, 46 (24), 4312-4314.

(3) Cao, S.-W.; Zhu, Y.-J. I. Phys. Chem. C 2008, 112 (16), 62536257.

(4) Zhang, H.; Zhu, Q.; Zhang, Y.; Wang, Y.; Zhao, L.; Yu, B. Adv. Funct. Mater. 2007, 17 (15), 2766-2771.

(5) Zhao, Q.; Gao, Y.; Bai, X.; Wu, C.; Xie, Y. Eur. J. Inorg. Chem. 2006, 2006 (8), 1643-1648.

(6) Lou, X. W.; Wang, Y.; Yuan, C.; Lee, J. Y.; Archer, L. A. Adv. Mater. 2006, 18 (17), 2325-2329.

(7) Poizot, P.; Laruelle, S.; Grugeon, S.; Dupont, L.; Tarascon, J. M. Nature 2000, 407 (6803), 496-499.

(8) Lou, X. W.; Deng, D.; Lee, J. Y.; Archer, L. A. Chem. Mater. 2008, $20(20), 6562-6566$.

(9) Ma, H.; Cheng, F.; Chen, J. Y.; Zhao, J. Z.; Li, C. S.; Tao, Z. L.; Liang, J. Adv. Mater. 2007, 19 (22), 4067-4070.

(10) Arico, A. S.; Bruce, P.; Scrosati, B.; Tarascon, J.-M.; van Schalkwijk, W. Nat. Mater. 2005, 4 (5), 366-377.

(11) Wang, X.; Wu, X.-L.; Guo, Y.-G.; Zhong, Y.; Cao, X.; Ma, Y.; Yao, J. Adv. Funct. Mater. 2010, 20 (10), 1680-1686.

(12) Skrabalak, S. E.; Chen, J.; Au, L.; Lu, X.; Li, X.; Xia, Y. Adv. Mater. 2007, 19 (20), 3177-3184.

(13) Chen, J.-F.; Ding, H.-M.; Wang, J.-X.; Shao, L. Biomaterials 2004, 25 (4), 723-727.

(14) Zhou, J.; Wu, W.; Caruntu, D.; Yu, M. H.; Martin, A.; Chen, J. F.; O'Connor, C. J.; Zhou, W. L. J. Phys. Chem. C 2007, 111 (47), 17473-17477.

(15) Sokolova, V.; Epple, M. Angew. Chem., Int. Ed. 2008, 47 (8), 1382-1395.

(16) Wei, W.; Ma, G.-H.; Hu, G.; Yu, D.; McLeish, T.; Su, Z.-G.; Shen, Z.-Y. I. Am. Chem. Soc. 2008, 130 (47), 15808-15810.

(17) Caruso, F.; Caruso, R. A.; Möhwald, H. Science 1998, 282 (5391), 1111-1114.

(18) Kim, S.-W.; Kim, M.; Lee, W. Y.; Hyeon, T. J. Am. Chem. Soc. 2002, 124 (26), 7642-7643.

(19) Imhof, A. Langmuir 2001, 17 (12), 3579-3585.

(20) Bao, J.; Liang, Y.; Xu, Z.; Si, L. Adv. Mater. 2003, 15 (21), $1832-1835$

(21) Kim, D.; Park, J.; An, K.; Yang, N.-K.; Park, J.-G.; Hyeon, T. J. Am. Chem. Soc. 2007, 129 (18), 5812-5813.

(22) Xiong, Y.; Wiley, B.; Chen, J.; Li, Z. Y.; Yin, Y.; Xia, Y. Angew. Chem., Int. Ed. Enol. 2005, 44 (48), 7913-7917.

(23) Sun, Y.; Xia, Y. Science 2002, 298 (5601), 2176-2179.

(24) Sun, Y.; Mayers, B.; Xia, Y. Adv. Mater. 2003, 15 (7-8), 641646.

(25) Cabot, A.; Puntes, V. F.; Shevchenko, E.; Yin, Y.; Balcells, L.; Marcus, M. A.; Hughes, S. M.; Alivisatos, A. P. J. Am. Chem. Soc. 2007, 129 (34), 10358-10360.

(26) Yin, Y.; Erdonmez, C. K.; Cabot, A.; Hughes, S.; Alivisatos, A. P. Adv. Funct. Mater. 2006, 16 (11), 1389-1399.

(27) Yin, Y.; Rioux, R. M.; Erdonmez, C. K.; Hughes, S.; Somorjai, G. A.; Alivisatos, A. P. Science 2004, 304 (5671), 711-714.

(28) Peng, S.; Sun, S. Angew. Chem. Int. Ed. 2007, 46 (22), 41554158.

(29) Fan, H. J.; Knez, M.; Scholz, R.; Nielsch, K.; Pippel, E.; Hesse, D.; Zacharias, M.; Gosele, U. Nat. Mater. 2006, 5 (8), 627-631.

(30) Higgin, J. M.; Carmichael, P.; Schmitt, A. L.; Lee, S.; Degrave, J. P.; Jin, S. ACS Nano 2011, 5, 3268-3277.

(31) Gaudet, S.; Detavernier, C.; Kellock, A. J.; Desjardins, P.; Lavoie, C. J. Vac. Sci. Technol., A: Vac., Surf., Films 2006, 24 (3), 474-485.

(32) Spann, J. Y.; Anderson, R. A.; Thornton, T. J.; Harris, G.; Thomas, S. G.; Tracy, C. Electron Device Lett. 2005, 26 (3), 151-153.

(33) Brunco, D. P.; De Jaeger, B.; Eneman, G.; Mitard, J.; Hellings, G.; Satta, A.; Terzieva, V.; Souriau, L.; Leys, F. E.; Pourtois, G.; Houssa, M.; Winderickx, G.; Vrancken, E.; Sioncke, S.; Opsomer, K.; Nicholas, G.; Caymax, M.; Stesmans, A.; Van Steenbergen, J.; Mertens, 
P. W.; Meuris, M.; Heyns, M. M. J. Electrochem. Soc. 2008, 155 (7), $\mathrm{H} 552-\mathrm{H} 561$.

(34) Yan, C.; Higgins, J. M.; Faber, M. S.; Lee, P. S.; Jin, S. ACS Nano 2011, 5 (6), 5006-5014.

(35) Zaima, S.; Nakatsuka, O.; Kondo, H.; Sakashita, M.; Sakai, A.; Ogawa, M. Thin Solid Films 2008, 517 (1), 80-83.

(36) Hsin, C. L.; Lee, W. F.; Huang, C. T.; Huang, C. W.; Wu, W. W.; Chen, L. I. Nano Lett. 2011, 11, 4348-4351.

(37) Chiu, C. H.; Huang, C. H.; Chen, J. Y.; Huang, Y. T.; Hu, J. C.; Chen, L. T.; Hsin, C. L.; Wu, W. W. Nanoscale 2013, 5, 5086-5092.

(38) Huang, C. W.; Hsin, C. L.; Wang, C. W.; Chu, F. H.; Kao, C. Y.; Chen, J. Y.; Huang, Y. T.; Lu, K. C.; Wu, W. W.; Chen, L. J. Nanoscale 2012, 4, 4702-4706.

(39) Chen, J. Y.; Hsin, C. L.; Huang, C. W.; Chiu, C. H.; Huang, Y. T.; Lin, S. J.; Wu, W. W.; Chen, L. I. Nano Lett. 2013, 13, 3671-3677. (40) Huang, Y. T.; Yu, S. Y.; Hsin, C. L.; Huang, C. W.; Kang, C. F.; Chu, F. H.; Chen, J. Y.; Hu, J. C.; Chen, L. T.; He, J. H.; Wu, W. W. Anal. Chem. 2013, 85, 3955-3960.

(41) Lee, K. Y.; Liew, S. L.; Chua, S. J.; Chi, D. Z.; Sun, H. P.; Pan, X. Q. Mater. Res. Soc. Symp. Proc. 2004, 55, 810-815.

(42) Tang, J.; Wang, C.-Y.; Xiu, F.; Lang, M.; Chu, L.-W.; Tsai, C.-J.; Chueh, Y.-L.; Chen, L.-J.; Wang, K. L. ACS Nano 2011, 5 (7), 60086015.

(43) Miu, K. Y.; Park, J.; Zheng, H.; Alivisator, A. P. Nano Lett. 2013, 13, 5715-5719.

(44) Railsback, J. G.; Peck, A. C.; Wang, J.; Tracy, J. B. ACS Nano 2011, 4, 1913-1920. 